\title{
Incommensurability, Incomparability, and God's Choice of a World
}

\section{Klaas J. Kraay}

Ryerson University

digital.library.ryerson.ca/object/46

Please Cite:

Kraay, K. J. (2011). Incommensurability, incomparability, and God's choice of a world. International Journal for Philosophy of Religion, 69(2), 91-102.

doi:10.1007/s11153-010-9266-1

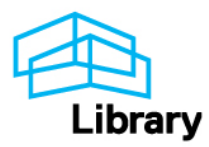




\title{
INCOMMENSURABILITY, INCOMPARABILITY, AND GOD'S CHOICE OF A WORLD
}

\author{
Klaas J . Kraay \\ Ryerson University
}

\begin{abstract}
This paper appears in the International J ournal for Philosophy of Religion 69 (2011): pp.91-102. The published version can be found online at: http:// www.springerlink.com/ content/14t7844jp358n071/fulltext.pdf.
\end{abstract}

\begin{abstract}
Anselmian theism holds that there necessarily exists a being, God, who is essentially unsurpassable in power, knowledge, goodness, and wisdom. This being is also understood to be the creator and sustainer of all that is. In contemporary analytic philosophy of religion, this role is generally understood as follows: God surveys the array of possible worlds, and in his wisdom selects exactly one for actualization, based on its axiological properties. ${ }^{1}$ In this paper, I discuss an under-appreciated challenge for this account of the Anselmian God's selection of a world. In particular, I urge that there are failures of comparability between various possible worlds, and I argue that, given certain assumptions, these failures threaten the rationality of God's choice of a world. To the extent that rationality is deemed necessary for unsurpassability, this result also challenges the core Anselmian notion that God is an unsurpassable being.
\end{abstract}

\section{SOME PRELIMINARY ASSUMPTIONS}

Discussions of God's choice of a world assume that worlds have axiological status, and that they can be evaluated: some are good, others are bad; some are better, others are worse. ${ }^{2}$ Here is one way to understand these claims. Whether possible worlds are taken to be concrete objects, abstract objects, or convenient fictions, it seems plausible to suppose that, if a world is actual, it can properly be said to bear - or fail to bear - world-good-making properties (hereafter WGMPs). These are properties which, if instantiated in a world, tend to make that world good, or at least better than it would otherwise be (ceteris paribus). ${ }^{3}$ Similarly, it seems reasonable to speak of world-bad-making properties (hereafter WBMPs): properties which, if instantiated in a world, tend to make a world bad, or at least worse than it would otherwise be (ceteris paribus). ${ }^{4}$ On this account, the overall axiological status of a given world can be understood to depend upon which WGMPs and WBMPs are in fact instantiated in that world, and (for degreed properties) the degree to which they are instantiated. ${ }^{5}$ In what follows, I assume this account.

I also assume two positions prevalent in the literature on rational choice. The first is the trichotomy thesis. ${ }^{6}$ This view holds that if two items $\mathrm{x}$ and $\mathrm{y}$ are axiologically comparable, then either $\mathrm{x}$ is better than $\mathrm{y}$, or $\mathrm{x}$ is worse than $\mathrm{y}$, or else $\mathrm{x}$ and $\mathrm{y}$ are equal in value. The second is comparativism. ${ }^{7}$ This view holds that only a comparative fact - specifically, a fact about the relative axiological status of some alternatives - can rationally ground one's choice between those alternatives. In what follows, I argue that God is faced with incomparable alternatives in choosing a world. 


\section{NECESSITARIANISM AND CONTINGENTISM}

Consider the set, S, which comprises all the WGMPs and WBMPs there actually are: this set, in effect, is a complete list of criteria according to which the overall axiological status of the actual world is to be measured. Necessitarianism (as I shall use the term), holds that there could not possibly have been different WGMPs and WBMPs than the ones there actually are: in other words, $\mathrm{S}$ is the only such set that there could possibly be. The denial of necessitarianism, which I call contingentism, holds that, indeed, there are alternative sets of WGMPs and WBMPs.

Why might anyone endorse contingentism? One line of support is inspired by Descartes. Notoriously, Descartes appears to have held that God's will determines not only what is obligatory and what is forbidden, but also what is good, and what is true:

[N]othing good or true, or nothing that is to be believed or done or omitted, can be imagined, for which the idea will have been in the divine intellect before God's will decides that it be of that kind as a result. Nor do I speak here of priority of time; it is not even prior in order, or nature, or the processes of reason (ratione ratiocinata), as they say - namely such that that idea of good impelled God to choose one thing over another. Certainly, to give an example, he did not thus will to create the world in time because he saw it to be better thus than if he created from eternity; nor did he will the three angles of a triangle to be equal to two right angles because he knew it could not be made another way, etc. On the contrary, because he willed to create the world in time, it is thus better so than if he had created from eternity, and because he willed the three angles of a triangle necessarily to be equal to two right angles, therefore now this is true and cannot be made in another way; and so on for the rest [emphasis added]. ${ }^{8}$

Because of the sovereignty this view accords to God's will, it is called theological voluntarism. ${ }^{9}$ One reason for being a contingentist, then, is the belief that God's will determines which properties are world-good-making and which are world-bad-making. ${ }^{10}$ To say that God could have willed otherwise in this domain, then, is to say that there is a set, $\mathrm{T}$, that comprises a different collection of WGMPs and WBMPs than S does. While S contains the actual list of properties selected by God, T is a set of properties that God might have chosen instead.

Contingentism might be thought to suggest the following picture: all possible worlds are, in fact, properly to be evaluated with reference to set S, but, had things turned out otherwise for example, had God willed differently - then all possible worlds would instead have properly been evaluated with reference to set $\mathrm{T}$. But this is a mistake. That set $\mathrm{S}$ is the proper collection of criteria to evaluate world $\mathrm{w}$ is a fact about $\mathrm{w}$ : accordingly, it is a feature of $\mathrm{w}$; a fact in w. Therefore, no world can be evaluated by more than one set of criteria, for if one purports to evaluate $\mathrm{w}$ by the criteria of $\mathrm{T}$, one is really evaluating a different world - a world in which $\mathrm{T}$ comprises the relevant criteria, not S. ${ }^{11}$ Accordingly, it cannot be held, on contingentism, that all possible worlds are to be evaluated by any one set of axiological criteria.

Instead, on contingentism, there are some possible worlds for which one set of axiological criteria are relevant, and there are other worlds for which a different set of properties is the appropriate standard. Let's stipulate that S constitutes the proper axiological standard for evaluating the actual world, w. On contingentism, then, there is at least one other world, $\mathrm{x}$, for which $\mathrm{T}$ is the appropriate standard instead. Let's say that a cluster is a set of all worlds which are subject to a given common standard of axiological evaluation. ${ }^{12}$ So there is a cluster, which includes the actual world $\mathrm{w}$, for which $\mathrm{S}$ is the appropriate standard, and there is a different cluster, which includes $\mathrm{x}$, for which $\mathrm{T}$ is the appropriate standard. ${ }^{13}$ (No one world, for the reasons given above, can belong to more than one cluster.) It follows that there are incommensurable ${ }^{14}$ pairs of worlds: pairs like $\mathrm{w}$ and $\mathrm{x}$ which - since they belong to different clusters - cannot be evaluated against a common axiological standard. Generalizing, we see that 
no two worlds from different clusters can be commensurable. ${ }^{15}$ One immediately obvious consequence is that the expression "best of all possible worlds" lacks a referent on contingentism: if it's not the case that all worlds are to be appraised by the same axiological standard, then no world can be deemed better than all the others.

As I use these terms, then, on necessitarianism there is exactly one cluster of worlds. On contingentism, however, there is more than one. How many? It's of course difficult to say, but the theological voluntarist (for example) should at least say that the number of clusters is determined, like everything else, by God's will. In Section 3, I consider some challenges to the rationality of God's choice of a world on contingentism, and in Section 4, I consider some further challenges relevant to both contingentism and necessitarianism.

\section{INCOMMENSURABILITY AND GOD'S CHOICE OF A WORLD ON CONTINGENTISM}

On contingentism, then, there are failures of comparability between worlds: since no two worlds from different clusters are commensurable, no two such worlds can be compared. ${ }^{16}$ In this section, I explore the implications of this view for God's choice of a world on contingentism.

Logically prior to God's choice of a world within some cluster, surely, is God's choice of which cluster to favour. ${ }^{17}$ But on what basis does God opt for one cluster over another? This choice cannot sensibly be grounded in the relative (de)merits of the worlds from various clusters, since inter-cluster judgments about worlds are impossible on contingentism.

God's choice of a cluster, then, must be based on something else. ${ }^{18}$ One might propose that God should base his choice of cluster on the relative (de)merits of the various sets of axiological properties governing worlds. On this suggestion, if the axiological properties of set $\mathrm{S}$ are somehow better, or more choiceworthy, than the properties of set $\mathrm{T}$, then God should choose the cluster of worlds for which set $\mathrm{S}$ is the appropriate standard of evaluation.

This is a rather mysterious proposal. It depends upon there really being a set of secondorder properties - properties about sets of axiological properties like $\mathrm{S}$ and $\mathrm{T}$ - that can undergird God's selection of a cluster. Such properties would have to be capable of revealing (for example) set $\mathrm{S}$ to be better, or more choiceworthy, than set $\mathrm{T}$, even though the worlds that are properly to be evaluated with reference to $\mathrm{S}$ are literally incomparable with worlds for which $\mathrm{T}$ is the appropriate standard. It is very difficult to imagine what such properties might be - and the burden of proof lies with the defender of this proposal to identify plausible candidates. But suppose we waive this worry, and grant that sets of axiological properties, like S and T, can themselves be ranked in this way.

Two difficulties remain. First, although we've stipulated that the clusters governed by S and $\mathrm{T}$ are both genuine logical possibilities, there is now reason for thinking that this cannot be so. We are supposing that the properties contained in $\mathrm{T}$ are worse - less choiceworthy - than those in S. But this means that God, who is after all a perfect being, simply could not choose a Tworld when an S-world is available, for to do so would be to prefer (absurdly, for God) the worse to the better. So, if S-worlds are available, no T-world can be actual, in which case T-worlds are not, after all, genuine logical possibilities on theism. ${ }^{19}$ Since this threatens the coherence of contingentism, it is hard to see how a contingentist can avail herself of this move.

Here is the second difficulty with this proposal. Suppose there is indeed a set, $\mathrm{S}^{*}$, of second-order properties according to which sets of properties like $\mathrm{S}$ and $\mathrm{T}$ can properly be evaluated. Is $\mathrm{S}^{*}$ the only such set that there could possibly be, or might there have been others? It will be difficult for the contingentist to remain consistent while maintaining the former alternative. Surely the considerations that support contingentism (particularly, for example, theological voluntarism) would suggest that the contingentist should likewise hold that there are alternative sets of second-order properties, different from $\mathrm{S}^{*}$. But in this case, one might sensibly ask why $\mathrm{S}^{*}$ in fact constitutes the appropriate criteria for evaluating sets like $\mathrm{S}$ and $\mathrm{T}$, 
rather than some other set of second-order properties. ${ }^{20}$ If the answer given appeals to some further set of third-order properties, $\mathrm{S}^{* *}$, we are enroute to a devastating regress problem.

On the basis of these considerations, I conclude that on contingentism, it is very difficult to see how God's choice of a cluster could be justified, given the assumptions concerning rational choice in play. In the next section, I consider further problems for God's choice of a world within a given cluster. This will be relevant to both contingentism and necessitarianism.

\section{INTRA-CLUSTER FAILURES OF COMPARABILITY}

On contingentism, there are various clusters of worlds. Inter-cluster axiological comparisons of worlds are not possible, due to incommensurability, but intra-cluster comparative axiological judgments are possible, since all worlds within a cluster are commensurable. On necessitarianism, there is just one cluster of worlds, since (as noted earlier) according to this view, all worlds are evaluated according to the one and only set of WGMPs and WBMPs that there could possibly be.

All worlds within a cluster are commensurable, but it doesn't follow that all worlds within a cluster are comparable. Indeed, several authors have argued or assumed that there can be failures of comparability between commensurable worlds, and others have offered arguments that can be deployed in support of this view. ${ }^{21}$ In this section, I canvass two reasons for thinking that there can be failures of comparability within a cluster. ${ }^{22}$

(a) MULTIPLE RANKINGS. One such argument proceeds from the claim that there can be multiple legitimate rankings of worlds, none of which is privileged. In explaining this argument, Ruth Chang (1997, 22-23) considers a comparison between two philosophers, Eunice and J anice, with respect to philosophical talent. Plausibly, there are multiple good-making properties of philosophers (originality, insightfulness, clarity of thought, clarity of expression, and the like), and perhaps there is no single best way to weigh the contributing effects of these on overall talent. Perhaps Eunice surpasses J anice with respect to some properties, but J anice surpasses Eunice with respect to others. If no such 'sharpening' is privileged, one might argue that the two philosophers are incomparable, even though they are commensurable with respect to the set of philosophical good-making properties. Such an argument can be generalized to worlds: if there are multiple legitimate ways to rank a pair of commensurable worlds with respect to a common set of axiological properties, they are incomparable.

(b) MINOR IMPROVEMENTS. Several philosophers have argued that when neither of two items surpasses the other, but when a minor improvement to one item fails to make it better than the other, it is reasonable to deem these items incomparable. Inspired by an example given by Raz (1986), Mann (1991, 270-1) imagines an individual's choice between two different careers. Teresa, in Mann's story, is faced with the choice between a vocation serving the dying poor in Calcutta, and a successful operatic career. ${ }^{23}$ Mann stipulates that neither option can be pursued fully without detriment to the other, and urges that neither option surpasses the other. Nor, says Mann, are they exactly equal, since this would mean (for example) that one additional outstanding performance of Tosca would - absurdly - make that career surpass the career in which Teresa serves the poor, and thereby justify Teresa's choice of a musical career. Again, such an argument can be generalized to worlds: if the states of affairs consisting in Teresa's alternative careers are incomparable, perhaps worlds that include them, ceteris paribus, are incomparable too. ${ }^{24}$

It is plausible to suppose that arguments such as these can support the conclusion that there are failures of comparability between (commensurable) worlds within a given cluster. 
Following Bruce Langtry (2008), let's use the term hierarchy to denote a subset of worlds within a cluster, each member of which is both commensurable with and comparable to all others in that set. The number of hierarchies within a cluster is, then, determined by the number of failures of comparability that there are between worlds within that cluster.

What sorts of hierarchies are there? Three relevant ${ }^{25}$ kinds suggest themselves. First, there may be hierarchies that feature exactly one unsurpassable world - a world that is better than all others in that hierarchy. Second, there may be hierarchies that feature multiple unsurpassable worlds. Third, there may be still other hierarchies that lack an unsurpassable world altogether: in these, there is an infinite ascending sequence of increasingly better worlds. ${ }^{26}$

\section{LANGTRY ON GOD’S CHOICE OF A HIERARCHY}

Bruce Langtry (2008) considers various questions about what sort of world God will choose, given different alternatives. (Langtry presumes necessitarianism in his discussion, though he does not say so explicitly. In any case, as noted, the question of how God selects a world within a cluster is relevant to both necessitarianism and contingentism.) Langtry thinks that if God decides to select a world from a hierarchy that has one or more unsurpassable members, God will choose one of those. He also thinks that if God decides to select a world from a hierarchy that contains no unsurpassable members, then God will satisfice: he will select a world that is good enough from the hierarchy. ${ }^{27}$ Both positions are controversial. ${ }^{28}$ For now, though, let's suppose that Langtry is correct in these claims, in order to turn to what he says about God's choice of a hierarchy. ${ }^{29}$

First, Langtry urges that if God is faced with a choice between hierarchy $\mathrm{H}$ (which has no unsurpassable members) and hierarchy J (which has such members), God will opt for hierarchy $\mathrm{J}$, and select an unsurpassable member from that set. ${ }^{30}$ Langtry next considers what God will do when deliberating between two hierarchies, $\mathrm{H}$ and $\mathrm{H}^{*}$, both of which have unsurpassable members. Langtry imagines God considering the choice between $\mathrm{v}$, a surpassable member of $\mathrm{H}$, and $\mathrm{w}$, an unsurpassable member of $\mathrm{H}^{*}$. Langtry says that God will choose w. ${ }^{31}$ Langtry's overall view, then, is this: when faced with a choice between different kind of hierarchies, God will opt for a hierarchy that features one or more unsurpassable worlds, and, further, God will select an unsurpassable world from within such a hierarchy.

I begin with a general worry for Langtry's proposal. Logically prior to God's choice of a world is, presumably, God's choice of a hierarchy.32 But on what basis might God prefer one hierarchy to another? Worlds from different hierarchies within a cluster are (by definition) incomparable, so it is difficult to see what basis there might be for preferring one hierarchy to another. Put differently, it is hard to see how one hierarchy could be thought more choiceworthy than another, when all worlds from within any hierarchy are incomparable with all worlds in every other hierarchy.

One response would be to insist that hierarchies can be thought more or less choiceworthy by appeal to some set of second-order properties capable of grounding comparative judgments. But this response is vulnerable to the first and second objections leveled against the similar proposal, noted in Section 3, concerning clusters: (1) it's difficult to imagine what these mysterious properties could be, and the defender of this proposal bears the burden of identifying plausible candidates; and (2) even if this proposal could be made to work, there is reason for thinking that less choiceworthy hierarchies would not represent genuine logical possibilities, on theism.

Perhaps, however, Langtry can offer a different response. He might claim that he does not owe an account of how incomparable hierarchies are to be compared: after all, Langtry concentrates on evaluating God's alternative actions in selecting from one hierarchy or another, rather than concentrating on the relative (de)merits of the hierarchy chosen. Langtry maintains 
that God acts in a better way by selecting an unsurpassable world from some hierarchy, instead of (a) selecting a surpassable world from the same hierarchy; or (b) selecting a surpassable world from some other hierarchy. To do this, however, Langtry needs to show that God's action in choosing from one hierarchy can sensibly be thought better than God's alternative action in choosing from another hierarchy, when the objects of choice (the worlds) are incomparable. It is difficult to see how such an argument might proceed. ${ }^{33}$

I doubt, then, that either response can be made to work. But even if I'm wrong about this, different problems remain: Langtry's analysis is too coarse-grained in two respects. First, Langtry's reasoning simply tells us that God will select an unsurpassable world from some hierarchy, over certain alternatives. But, suppose that there are two hierarchies, $\mathrm{H}$ and I, that both feature exactly one unsurpassable world. On what basis could God, consistent with his goodness, wisdom, and other attributes, select the unsurpassable world from either cluster? Both candidates for selection are unsurpassable (relative to their cluster, of course), but they are also incomparable with each other. It seems that God's decision to select one or the other must be groundless, and hence - on comparativism - irrational. The same objection can be leveled, mutatis mutandis, against Langtry's understanding of a choice situation in which God chooses between two or more hierarchies, each of which feature multiple unsurpassable worlds.

There is a second respect in which Langtry's model is too coarse-grained. Suppose with Langtry that God could (somehow) justifiably select a hierarchy that contains more than one unsurpassable world. How is God to choose from among these unsurpassable (and comparable) alternatives? It would seem, on comparativism, that God could have no sufficient reason for selecting any one of the unsurpassable worlds over all the others. ${ }^{34}$ But it is standardly assumed that God must have a sufficient reason for selecting whichever world is actual. ${ }^{35}$ Accordingly, Langtry's account fails adequately to explain how God can, consistent with his attributes, defensibly select one unique world from a range of choices spread out over multiple hierarchies.

\section{CONCLUSION}

Either contingentism or necessitarianism is true. If contingentism is true, there are failures of comparability between worlds, since no two worlds from different clusters can sensibly be compared. Logically prior to God's selection of a world is God's choice of a cluster. But, given comparativism, it is difficult to see how God's choice of a cluster could be rationally justified. While all worlds within a cluster are commensurable, it doesn't follow that all worlds within a cluster are comparable. There are good reasons to think that there are failures of comparability between worlds within the same cluster. If there are such failures, problems arise for the rationality of God's choice of a hierarchy within a given cluster. These problems affect both contingentism and necessitarianism. Therefore, no matter whether contingentism or necessitarianism is true, there are serious difficulties for the core theistic claim that God's choice of a world from among many alternatives is rational. And this, in turn, threatens the traditional notion that God is a perfect being, since it is plausible to expect the choices of such a being particularly on such an important matter as selection of a world - to be rationally defensible.

If I'm right that, no matter what, God faces a choice between incomparable worlds, the theist can respond in two ways. One is to insist that God's choice between incomparable items can indeed be considered rational. The other is to concede that God's choice of a world cannot be rational, but to insist that this result does not impugn God essential perfection. The former strategy amounts to a denial of comparativism. For this to succeed, the theist either needs to deny this view outright, or at least must offer reasons why it is implausible in the context of God's choice of a world. ${ }^{36}$ As for the latter strategy: for this to succeed, the theist owes a plausible account of why God's imperfect rationality does not, contrary to what we might initially suppose, entail that God is imperfect. Either way, the burden of proof now rests with the theist. 


\section{ACKNOWLEDGEMENTS}

I am very grateful to Nathan Ballantyne, David Efird, Luke Gelinas, Bruce Langtry, Tim Mawson, Yujin Nagasawa, Graham Oppy, Myron Penner, and Ed Wierenga for stimulating and helpful discussions of previous drafts.

\section{NOTES}

${ }^{1}$ When God selects a world for actualization, God causes it to be the case that one world rather than another is actual. It is sometimes tempting to imagine that, in so doing, (a) God stands outside the set of possible worlds; that (b) God always creates something; and that (c) God determines each and every feature of the ensuing world (d) all at once. Elsewhere (in Kraay 2008a), I argue that the first two assumptions are false, and that the latter two are not required by theism.

2 I do not mean to suggest that worlds can be cardinally ranked - an ordinal ranking will do.

3 Candidate WGMPs pick out a property held to be good-making. Traditional examples include: the presence of free moral agents in the world; the favourable balance of moral actions over immoral ones; the variety of phenomena in the world; and the simplicity of a world's governing laws.

4 The most frequently discussed candidate WBMP is the presence of gratuitous suffering in the world. On the Augustinian view according to which evil is in fact the absence of good (privatio boni), every WBMP would presumably refer to the absence of a WGMP. There may be such WBMPs, and there may also be WBMPs that are the contraries of WGMPs, and there may be still other, different, WBMPs. I remain neutral on this; nothing turns on it for my purposes.

5 Of course, it may be that certain good-making properties cease to make worlds better past a certain point, or in certain combinations. The same goes, mutatis mutandis, for WBMPs. So, while the goodness of a world depends on its axiological properties, this dependency may not be simple. This is the point of the ceteris paribus clause in the definitions of WGMPs and WBMPs.

6 This term is due to Chang $(1997,4)$, who notes that this thesis is almost universally assumed in the literature on rational choice. Many authors also assume it in the literature on God's choice of a world: see, for example, Flint (1983), Mann (1991), Grover (1998), and Langtry (2008). Chang herself, however, denies the trichotomy thesis. She thinks there is a fourth relation - parity - and maintains that this can help solve some puzzles for rational choice. I do not believe that parity can solve the challenges posed below for God's choice of a world, but space does not permit developing this argument here.

7 This term is also borrowed from Chang $(1997,9)$, although my definition is more precise than hers. Chang merely defines comparativism as "the view that all choice situations are comparative". Chang defends comparativism against a series of objections.

8 Adam, C. and Tannery, P. Oeuvres de Descartes (Vol.7), 431-432. Translation by William Mann (1991, 258.)

9 Many philosophers have found this sort of voluntarism repugnant. For example, Leibniz writes:

In saying, therefore, that things are not good according to any standard of goodness, but simply by the will of God, it seems to me that one destroys, without realizing it, all the love of God and all his glory, for why praise him for what he has done, if he would be equally praiseworthy for doing the contrary? Where will be his justice and his wisdom if he has only a certain despotic power, if arbitrary will takes the place of reasonableness, and if in accord with the definition of tyrants, justice consists in that which is pleasing to the most powerful? Besides it seems that every act of 
willing supposes some reason for the willing and this reason, of course, must precede the act (Discourse on Metaphysics, §2).

I do not think that these points constitute a refutation of theological voluntarism (still less of contingentism) - but they do suggest difficulties for any account of God's choice of a world on this view. I develop such difficulties in Section 3.

10 Contingentism does not entail theological voluntarism; one might be a contingentist for other reasons. Theological voluntarism, however, entails contingentism.

11 There may be other constraints. Suppose, for example, that the axiological properties of worlds supervene on natural characteristics of those worlds. If so, then no two worlds with the same natural characteristics can be governed by different axiological properties.

12 The term 'cluster' is due to Mann (1991, 271), although he uses it to refer to what I will in Section 4 call (following Langtry 2008) a 'hierarchy'. Flint (1983) uses the term 'galaxy' for what Langtry and I call a hierarchy'. I do not assume that every cluster has more than one member. But I do assume that every possible world is appropriately subject to some standard of axiological evaluation.

${ }^{13}$ It may even be that the axiological standards of $\mathrm{T}$ appear abhorrent from the perspective of a world governed by S: perhaps, for example, properties considered good-making in S are bad-making in T, and vice-versa. One vivid depiction of this idea can be found in the idea of Bizarro World that periodically crops up in the Superman comic book series. The inhabitants of this topsy-turvy planet swear allegiance to the Bizzaro code, which can be seen in the left panel below. The results can be seen in the right panel:
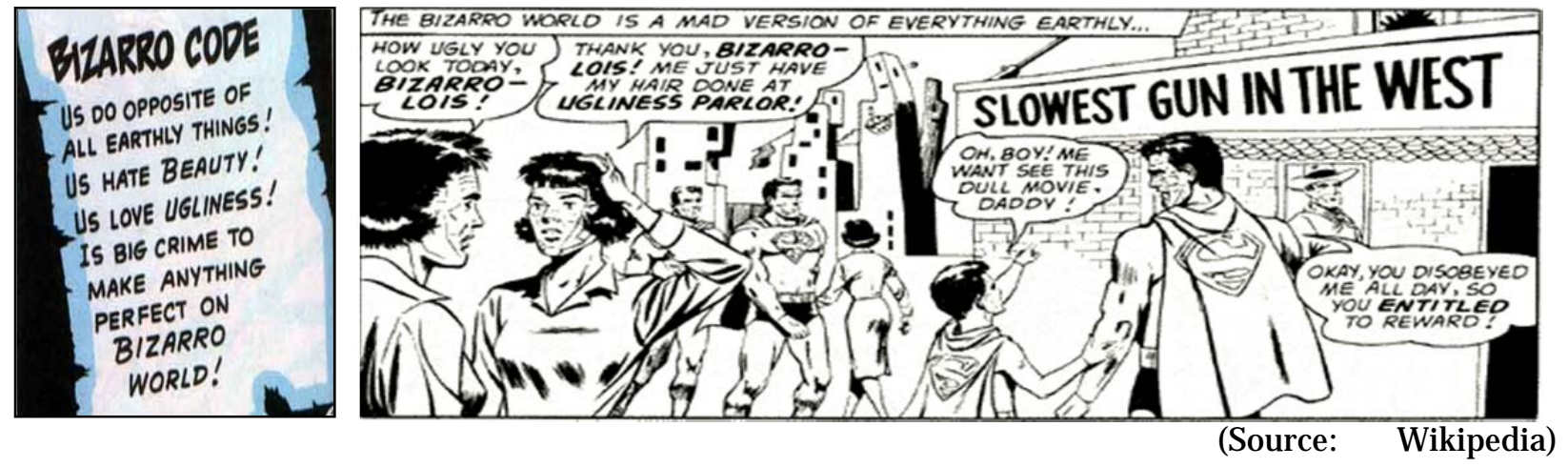

${ }^{14}$ See Hsieh (2007) for a nice survey of the myriad ways this term has been used. Chang calls these formal failures of comparability, as opposed to substantive failures $(1997,29)$. I consider the latter in Section 4.

15 It may be that incommensurability comes in degrees: the more the sets of properties governing two distinct clusters differ, the more incommensurable worlds from those clusters are. (I thank Luke Gelinas for suggesting this.) Space does not permit exploring just how this would go.

16 When two worlds are incommensurable, they cannot be compared. As we'll see below (in Section 4), however, it does not follow that all commensurable worlds are comparable: there are good reasons for thinking that there are failures of comparability between commensurable worlds.

17 In correspondence, Nathan Ballantyne has suggested that God might just choose a world, without first (as a matter of logical priority) deliberating about which cluster to choose. Perhaps God can do this, but it remains the case that God is both aware of and responsible for, the choice of that cluster. Accordingly, God's choice of a cluster can properly be subject to evaluation.

${ }_{18}$ Comparativism, recall, stipulates that rational choice in this domain must be grounded in axiological comparison of alternatives. 
19 This argument is connected to a challenge to theism known as the modal problem of evil. God is a traditionally held to be a necessary being - one who exists in all possible worlds. And it seems plausible to suppose that there are very bad possible worlds - ones that would be morally impermissible for God to actualize. But if God is a necessary being who is the creator and sustainer of all that is, then in such worlds, God is responsible for their being actual. Since this is unacceptable, Guleserian (1983) claims, theists should either give up their belief in God, or dramatically revise their understanding of the divine attributes. In response, Morris (1987) urges that on theism, bad worlds are simply impossible, despite our modal intuitions and judgments to the contrary. In contrast, Almeida (forthcoming) responds by suggesting that since bad worlds necessarily exist, God cannot be blamed for their existence. Evidently, I prefer Morris' response to Almeida's. In any case, moves from this debate can be applied, mutatis mutandis, to the issue under consideration here.

20 One might be inclined to think that this argument is in tension with my earlier claim that no possible world can be evaluated by more than one set of axiological criteria, since I here suggest that, on contingentism, one set of axiological criteria should be thought capable of being evaluated by more than one set of second-order criteria (should there be such second-order properties). But there is no tension here. The reason for my earlier claim is simply this: to change the axiological criteria for a world just is to change the world. Accordingly, it is false that one world can be evaluated by more than one set of axiological criteria. But no parallel reason exists in this case. There is no reason to think that changing the second-order properties entails a change in the axiological properties themselves. The former are (mysterious) properties of sets of properties, while the latter are properties of worlds.

${ }^{21}$ See, for example, Flint (1983), Mann (1991), and Langtry (2008).

22 For surveys of other arguments in defence of incomparability, see Chang (1997, 13-27) and Hsieh (2007, Section 3). Chang considers the two I discuss here to be the most plausible, though she thinks neither is decisive. Space does not permit an evaluation of Chang's claims in this regard.

${ }^{23}$ I here assume that there is one stable set of axiological properties that can be used to evaluate both careers: in other words, I assume that these careers are commensurable. Perhaps this seems extravagant, given the vast differences between these careers - but the example can easily be adapted to avoid this impression.

24 Grover (1998) criticizes Mann's argument. Space does not permit an examination of Grover's arguments.

${ }^{25}$ No doubt there are many ways to categorize hierarchies. But the three types identified below are the most significant for the problem of God's choice of a world. They are also the three types discussed by Flint (1983) and Langtry (2008).

26 Vividly, Flint (1983) terms these three types of hierarchy "monarchic", "oligarchic", and "anarchic", respectively.

${ }^{27}$ Flint (1983) agrees.

${ }^{28}$ Famously, Robert Adams (1972) has suggested that God is not obliged to select the best alternative from a series of worlds. Langtry's account of satisficing has been criticized by Rowe (2004) and Kraay (2005).

29 One might think that Langtry has overlooked an important possibility: perhaps there is one world that is comparable to, and better than, all others within a given cluster, even though there are failures of comparability within a cluster. (An analogy: perhaps a Ford Focus is incomparable with a Chevy Aveo, but perhaps a Toyota Matrix is comparable to, and better than, both.) If there were such a world, one might plausibly suppose, God would certainly choose it. It's true that Langtry fails to consider this scenario, but the burden of proof lies with those who think it is a genuine possibility to offer substantive reasons for 
thinking this so. (I thank Yujin Nagasawa, Graham Oppy, and Ed Wierenga for discussing this point with me.)

30 Here's what Langtry says (note that he uses 'create' where I use 'actualize', and 'prime' where I use 'unsurpassable'):

Given that there are both $\mathrm{H}$ and $\mathrm{J}$, whichever specific member of $\mathrm{H}$ God were to create he would act in a better way if he created some other world instead ... On the other hand, if God were to create some prime member of $\mathrm{J}$, then he will not have better reasons for creating some non-prime world instead. Therefore God acts in a better way, all things considered, if he creates a prime member of $\mathrm{J}$ than if he creates some member of $\mathrm{H}$. Therefore his perfect goodness guarantees that if God creates a world then he will create some prime member of J (108).

${ }^{31}$ Here's what Langtry says (note that he uses 'create' where I use 'actualize', and 'prime' where I use 'unsurpassable'):

[I]f God creates v then he has better reasons for creating some other world instead - a better member of $\mathrm{H}$ - whereas if God creates w then he does not have better reasons for creating some other world instead. Therefore, despite the fact that $\mathrm{v}$ and $\mathrm{w}$ are incommensurable, God acts in a better way if he creates $\mathrm{w}$ than if he creates $\mathrm{v}$. Therefore God's perfect goodness guarantees that if God creates a world then he will create some prime world (109).

32 See note 17 above.

${ }^{33} \mathrm{~A}$ third (and more radical) response might deny that God requires any basis at all for preferring one hierarchy, or one act of selection, to another. If this is correct, God might simply select a hierarchy at random, for example. But of course, this view is precluded by comparativism. For a set of worries about God's use of randomizers, see Kraay (2008b).

34 Blumenfeld (1975, 166; 1994, 396) and Strickland (2006, 142-3) attribute this worry to Leibniz.

35 Lloyd Strickland (2006) points out that in ordinary human affairs, when rational choice is thwarted by the absence of sufficient reasons, practical considerations make it reasonable for us to choose at random. Equally, he urges, in a case like this God could justifiably select a world at random. I criticize this argument in Kraay (2008b).

36 In a conference commentary on an earlier draft of this paper, Myron Penner attempts this move, by urging that God should not be thought irrational for choosing between incomparable items, when such a choice is unavoidable. So, since God cannot help but choose between incomparable worlds, God should not be deemed irrational. I do not think that his response succeeds: in fact, I think it begs the question. In effect, Penner assumes that a perfectly rational world-chooser is possible, and, on this basis, urges that this being can choose between incomparables without being less than perfectly rational. But it is illegitimate to assume that a perfectly rational world-chooser is possible in this context, for that is just the question at issue. For Penner's argument to succeed, reasons must be offered for thinking such a being possible - reasons that outweigh the probative force of the comparativist considerations. 


\section{References}

Adam, C. and Tannery, P. (1970). Oeuvres de Descartes, Volume 7. Paris, J . Vrin.

Adams, R. (1972). Must God Create the Best? Philosophical Review, 81, 317-332.

Almeida, M. (forthcoming). Theistic Modal Realism. Oxford Studies in Philosophy of Religion, 3.

Blumenfeld, D. (1975). Is the Best World Possible? J ournal of Philosophy, 84, 163-177.

(1994). Perfection and Happiness in the Best Possible World. In N. Jolley (Ed.), The Cambridge Companion to Leibniz (pp.382-410). Cambridge: Cambridge University Press.

Chang, R. (1997). Incommensurability, Incomparability, and Rational Choice. Cambridge: Harvard University Press.

Flint, T. (1983). The Problem of Divine Freedom. American Philosophical Quarterly, 20, 255264.

Grover, S. (1998). Incommensurability and the Best of All Possible Worlds. The Monist, 81, 648668.

Guleserian, T. (1983). God and Possible Worlds, The Modal Problem of Evil. Nous, 17, 221-238.

Hsieh, N. (2007). Incommensurable Values. Stanford Encyclopedia of Philosophy, http:// plato.stanford.edu/ entries/value-incommensurable/.

Kraay, K. (2005). William L. Rowe's A Priori Argument for Atheism. Faith and Philosophy, 22, 211-234.

(2008a). Creation, World-Actualization, and God's Choice Among Possible Worlds. Philosophy Compass, 3, 854-72.

(2008b). Can God Choose a World at Random? In E. Wielenberg, and Y. Nagasawa, (Eds.), New Waves in Philosophy of Religion (pp.22-35). Houndsmills: Palgrave MacMillan.

Langtry, B. (2008). God, the Best, and Evil. Oxford, Oxford University Press.

Leibniz, G.W. (1989). Discourse on Metaphysics; Correspondence with Arnauld; Mondology [G. Montgomery, Trans.], La Salle: Open Court.

Mann, W. (1991). The Best of all Possible Worlds. In S. MacDonald (Ed.), Being and Goodness (pp.250-277). Cornell: Cornell University Press.

Morris, T. (1987). Anselmian Explorations: Essays in Philosophical Theology, Notre Dame: University of Notre Dame Press.

Raz, J . (1986). The Morality of Freedom, Oxford: Clarendon Press. 
Rowe, W. (2004). Can God Be Free?, Oxford: Oxford University Press.

Strickland, L. (2006). God's Problem of Multiple Choice. Religious Studies, 42, 141-157. 